\title{
Ensino remoto na Educação Infantil em tempos de pandemia: reflexões acerca das novas formas de ensinar
}

\section{Remote education in the Children Education in times of pandemic: reflections regarding to the new ways of teaching}

\author{
${ }^{1}$ Edilma Mendes Rodrigues Gonçalves edilmamendes@cte.uespi.br \\ ${ }^{1}$ Ana Luiza Floriano de Moura Britto
}

\section{RESUMO}

A educação infantil de forma remota exige que as famílias disponham de equipamentos apropriados para o acompanhamento das atividades virtuais repassadas pela escola, além de conhecimentos pedagógicos para o ensino de crianças de 0 a 5 anos, que tem como eixos pedagógicos as interações e a brincadeira. $\mathrm{O}$ objetivo deste estudo é analisar a concepção de pais sobre o ensino remoto na Educação Infantil. É uma pesquisa descritiva qualiquantitativa, desenvolvida nos meses de maio e junho de 2020, por meio de um formulário online produzido no Google Forms e divulgado nas redes sociais para a coleta dos dados. Participaram da pesquisa pais de crianças que estudam em instituições de educação infantil, de diversas cidades do Brasil, com as aulas presenciais suspensas desde março de 2020 para evitar a propagação da COVID-19. Os resultados foram apresentados em uma Roda de Conversa Virtual no Google Meet, promovendo um diálogo entre pais, professores e estudantes do curso de pedagogia. Diante das discussões apresentadas, conclui-se que as atividades de forma remota não contribuem para a aprendizagem e desenvolvimento da criança de 0 a 5 anos, pois o trabalho desenvolvido nas creches e pré-escolas possibilita vivenciar experiências relacionadas aos saberes e conhecimentos, a serem apropriadas pelas crianças, o que não se torna possível em um ambiente doméstico.

Palavras-chave: Educação Infantil. Ensino remoto. Pandemia.

\begin{abstract}
The children education in a remote way demands the families to afford appropriate equipment to the accompaniment of the virtual activities passed on by the school, beyond pedagogical knowledges to teaching children between 0 and 5 years old, which has, as pedagogical axis, the interactions and the kidding. The aim-of this study is to analyze the conception of the parents on the remote education in the Children Education. It is a qualitative and quantitative research, developed in the months of May and June, the year of 2020, by means of an online application produced in the Google Forms and unveiled in the social networks for the data collection. Participated in this research parents of kids which study in children education institutions, from diverse cities of Brazil, with the in-class lectures suspended since 2020 March to avoid the propagation of the COVID-19. The results were presented in an Virtual Conversation Wheel via Google Meet, promoting dialogues among the parents, teachers and undergraduates of the Psychology course. In view of the discussions presented, it concludes that activities remotely conduced do not contribute to the learning and development of children aged 0 to 5 years, as the work developed in daycare centers and preschools makes it possible to live experiences related to knows and to knowledges to be appropriate for children, which is not possible in a domestic environment.
\end{abstract}

Keywords: Children Education. Remote Education. Pandemic.

1 Universidade Estadual Do Piauí - UESPI 


\section{INTRODUÇÃO}

A Educação Infantil é a primeira etapa da Educação Básica e tem como objetivo educar e cuidar de crianças de zero a cinco anos de idade em creches e pré-escolas. De acordo com as Diretrizes Curriculares Nacionais para a Educação Infantil (DCNEI), os eixos norteadores das práticas pedagógicas para essa etapa de ensino são as interações e as brincadeiras que devem garantir experiências diversas para que a criança aprenda e se desenvolva de forma integral (BRASIL, 2010).

As creches e as pré-escolas têm ganhado destaque em seus aspectos pedagógicos com um currículo que organiza o ensino para um atendimento educacional que visa ao desenvolvimento da criança em seus aspectos cognitivo, afetivo, social e psicológico. Segundo a Base Nacional Comum Curricular (BNCC), as crianças devem vivenciar experiências nas quais possam construir e se apropriar de conhecimentos por meio de suas ações e interações com adultos e outras crianças, o que possibilita a aprendizagem e o desenvolvimento (BRASIL, 2017).

Por meio das interações e das brincadeiras, as instituições de Educação Infantil oportunizam a criança a conviver em um ambiente de socialização, aprendendo sobre sua cultura e utilizando diferentes linguagens no processo de construção do conhecimento. Nesses ambientes, as crianças são consideradas como sujeito histórico, de direito, que aprende e se desenvolve no processo das interações sociais e com capacidades próprias de agir e pensar o mundo do seu jeito.

Dessa forma, surge a necessidade de discutir sobre as atividades remotas na educação das crianças de zero a cinco anos neste período de isolamento social e da suspensão temporária das aulas presenciais para evitar a propagação da COVID-19, uma doença respiratória causada pelo novo coronavírus identificado em dezembro de 2019 na China, com alto índice de contaminação entre as pessoas.

Neste contexto atual, as escolas públicas e privadas de todo o país buscam alternativas e estratégias de ensino para manter seus alunos engajados com as aulas e as atividades remotas na Educação Infantil, a fim de garantir a aprendizagem e o desenvolvimento das crianças durante a pandemia. Diante disso, este estudo apresenta o resultado de uma pesquisa on-line que tem como objetivo analisar a concepção de pais sobre o ensino remoto na Educação Infantil.

A investigação foi desenvolvida nos meses de maio e junho de 2020, por meio de um formulário on-line divulgado nas redes sociais para a coleta dos dados. Para apresentar os resultados, foi feita uma roda de conversa virtual, com o fito de promover um debate sobre a concepção dos pais, como também dos professores e dos estudantes do curso de Pedagogia diante dessa nova forma de ensino. O estudo apresentado contextualiza a Educação Infantil nas leis, nas diretrizes e nos documentos que direcionam essa etapa de ensino nas creches e nas pré-escolas.

\section{ENCAMINHAMENTOS METODOLÓGICOS}

Para a realização desta pesquisa, ressalta-se a importância de se definir a metodologia do estudo proposto. Nesse entendimento, na perspectiva dos objetivos, a pesquisa se classifica como descritiva, uma vez que busca descrever determinada realidade, a partir de observações, análises e descrições minuciosas (MOREIRA; CALEFFE, 2006, p.70). O estudo apresenta abordagem qualiqualitativa, na medida em que foram usados métodos tanto qualitativos, quanto quantitativos, como diz Flick (2004) no sentido de que os referidos métodos podem trabalhar juntos, de diferentes formas, considerando o planejamento do trabalho. Para esse autor, a união dos resultados qualitativos e quantitativos apresenta alguns objetivos. São eles: “[...] obtenção de um conhecimento sobre o tema do estudo que seja mais amplo do que uma única abordagem proporcionaria; ou validação mútua das descobertas de ambas as abordagens.” (FLICK, 2004, p. 276). 
Para o desenvolvimento do estudo, realizou-se toda a pesquisa com a utilização das plataformas digitais, diante do contexto da pandemia de COVID-19, uma doença respiratória aguda causada pelo coronavírus da síndrome respiratória aguda grave 2 (SARS-CoV-2), de expansão global, que levou grande parte da população mundial para dentro de casa, de forma a cumprir as determinações da Organização Mundial de Saúde (OMS) quanto ao isolamento social.

Desse modo, no âmbito do estado do Piauí, é importante ressaltar o Decreto n. ${ }^{\circ}$ 18.884, de 16 de março de 2020 que dispõe sobre as medidas de emergência de saúde pública de importância internacional, tendo em vista a classificação da situação mundial do novo coronavírus como pandemia. Nesse contexto, as aulas nas escolas foram suspensas, iniciando, assim, as discussões e as reflexões acerca das aulas remotas. No caso do presente estudo, dialoga-se acerca do ensino remoto na Educação Infantil, considerando o Parecer n. ${ }^{\circ}$ 5/2020, de 28 de abril de 2020, do Conselho Nacional de Educação, que trata das mudanças no calendário e delineia algumas orientações direcionadas para a comunidade escolar.

Assim, diante das explicitações acima relatadas, reitera-se que o estudo foi realizado nos meses de maio e junho de 2020, utilizando como técnica de produção de dados um formulário online produzido no Google Forms, que se apresenta, nesse contexto de pandemia, como lócus da pesquisa. É importante salientar, nesse ensejo, antes de apresentar a estrutura do formulário, que a pesquisa foi realizada com pais e/ou responsáveis de crianças matriculadas na Educação Infantil, com vistas a refletir sobre a opinião deles a respeito da inserção das aulas remotas na rotina de crianças de zero a cinco anos. Reitera-se que a pesquisa contou com a participação de 53 pais e/ou responsáveis, sem a necessidade de identificação.

Todavia, na perspectiva deste trabalho, analisam-se cinco questões. Essas contemplam assuntos referentes à instituição e à idade da criança, dialogam também com reflexões em relação à opinião dos pais quanto às aulas remotas, sobre a descrição das atividades oferecidas pelas escolas, as dificuldades enfrentadas nessa nova realidade, dentre outros temas. Dessa forma, no primeiro momento, aplicou-se o formulário online, disponibilizado por meio de link nas redes sociais.

No segundo momento da pesquisa, como forma de refletir e debater a respeito dos dados produzidos no estudo, realizou-se uma roda de conversa virtual. Nessa perspectiva, evidenciam-se os estudos de Moura e Lima (2014) que tratam sobre a possibilidade de fala e escuta, na utilização das rodas de conversa, evidenciando os momentos de debate e de compartilhamento de conhecimentos. "[...] é um momento singular de partilha, porque pressupõe um exercício de escuta e de fala, em que se agregam vários interlocutores, e os momentos de escuta são mais numerosos do que os de fala”. (MOURA; LIMA, 2016, p. 100).

Observa-se, assim, que esse momento de compartilhamento de ideias é fundamental diante do contexto de isolamento social e que as rodas de conversa promovem essa construção de diálogos e conhecimentos. Desse modo, o exercício de escuta e fala fora desenvolvido na roda de conversa virtual proposta no trabalho, com a participação de pais de alunos da Educação Infantil, professores e alunos de graduação.

Dessa forma, os resultados do estudo foram debatidos, utilizando a plataforma digital Google Meet. Inicialmente, os debatedores da roda de conversa apresentaram a legislação e os documentos curriculares que fundamentam a Educação Infantil no Brasil. Em seguida, foram discutidos os resultados da pesquisa realizada com pais de crianças matriculadas na Educação Infantil, e, em seguida, à apresentação de propostas de atividades que possam ser realizadas de forma remota, as quais contribuam para o desenvolvimento da criança de zero a cinco anos. A análise dos dados foi delineada a partir da definição de categorias de análise, em observância às respostas dos sujeitos da pesquisa, baseada na análise de conteúdo, proposta por Bardin (2011). 


\section{ENSINO REMOTO NA EDUCAÇÃO INFANTIL: DIÁLOGO POSSÍVEL?}

As instituições de Educação Infantil, neste ano de 2020, estão tentando se adaptar a uma realidade imposta pela COVID-19. Para evitar a transmissão dessa doença, fez-se necessário um isolamento social de forma rigorosa de toda a população brasileira, o que afetou diversos setores, como a indústria, o comércio, a cultura, o esporte e a educação com o fechamento de escolas, trazendo grandes desafios para alunos, pais e professores.

Nesse contexto, os estados e os municípios, por meio dos seus Conselhos de Educação, orientam com pareceres e/ou resoluções que as instituições de ensino reorganizem o calendário escolar e, assim, tentam se reinventar virtualmente em um cenário em que poucos alunos têm acesso à internet ou uma estrutura familiar capaz de fazer um acompanhamento educacional adequado. Desse modo, surge a necessidade de que se repensem a educação formal e o papel da escola, principalmente, quanto à Educação Infantil e ao processo de desenvolvimento e aprendizagem da criança de zero a cinco anos que tem como eixos norteadores das práticas pedagógicas as interações e a brincadeira.

Refletir sobre o ensino remoto na Educação Infantil faz reconhecer as especificidades do fazer pedagógico nessa etapa que busca superar o assistencialismo derivado do seu contexto histórico e que, somente a partir da Constituição Federal de 1988, teve reconhecido o seu caráter educativo, em que o Estado passou a ser responsável por garantir a Educação Infantil para todas as crianças. Além disso, outras conquistas foram obtidas com a Lei de Diretrizes e Bases da Educação Nacional (LDB), de n. ${ }^{\circ}$ 9.394/1996, que reconhece a referida etapa de ensino como a primeira da Educação Básica, explicitando, no artigo 29, que a Educação Infantil "[...] tem como finalidade o desenvolvimento integral da criança de até 5 (cinco) anos, em seus aspectos físico, psicológico, intelectual e social, complementando a ação da família e da comunidade” (BRASIL, 1996, p. 1).

Para orientar o trabalho pedagógico nessa etapa de ensino, em 1998, é lançado o Referencial Curricular Nacional para a Educação Infantil (RCNEI), trazendo um novo olhar sobre como as crianças constroem o conhecimento, objetivando melhorar a qualidade no ensino das creches e das pré-escolas e orientando para que as relações entre o educar e o cuidar se consolidassem como integrantes do processo educativo de forma indissociável (BRASIL, 1988).

Em 1999, foram instituídas pelo Conselho Nacional de Educação (CNE) as Diretrizes Curriculares Nacionais para a Educação Infantil (DCNEI), que definem melhor a Educação Infantil como a primeira etapa da Educação Básica, devendo ser “[...] oferecida em creches e pré-escolas, as quais não se caracterizam como espaços institucionais não domésticos que constituem estabelecimentos públicos ou privados que educam e cuidam de crianças de 0 a 5 anos de idade” (BRASIL, 2010, p. 12). As DCNEI fortalecem a oferta do ensino infantil público e de qualidade, sem requisito de seleção como um dever do Estado, e orientam as instituições sobre a organização do ensino, a articulação das propostas pedagógicas e a avaliação.

Então, considerando as interações e a brincadeira como eixos estruturantes das práticas pedagógicas, conforme preconizam as DCNEI, a Base Nacional Comum Curricular de 2017 propõe a organização curricular para a Educação Infantil por meio dos campos de experiências que buscam garantir os direitos de aprendizagem e desenvolvimento de todas as crianças de zero a cinco anos.

A BNCC assegura aprendizagens essenciais na Educação Infantil e reconhece que, além do educar e do cuidar como eixos indissociáveis nesse processo, “[...] a interação durante o brincar caracteriza o cotidiano da infância, trazendo consigo muitas aprendizagens e potenciais para o desenvolvimento integral das crianças" (BRASIL, 2017, p. 35).

Desse modo, a expectativa é que a criança vivencie, em espaços escolares, situações diversas de aprendizagem, que as possibilitem desenvolver as suas potencialidades por meio de atividades planejadas, com vista 
nas brincadeiras livres e nas situações de interações com adultos e outras crianças. Mas, diante do atual contexto de pandemia mundial, as instituições de Educação Infantil, públicas e privadas, estão fechadas desde março de 2020 sem ofertar atendimento presencial para as crianças de todo o país.

Nesse sentido, o Parecer do CNE n. ${ }^{\circ}$ 5/2020 orienta sobre as atividades pedagógicas não presenciais em razão da pandemia de Covid-19 e sugere que as instituições de ensino infantil desenvolvam materiais de orientações aos pais ou responsáveis com atividades educativas de caráter lúdico, recreativo, criativo e interativo, a serem realizadas com as crianças em casa, enquanto durar o período de isolamento social. Essas orientações desafiam as possibilidades da oferta do ensino infantil de forma remota, pois a educação de crianças de zero a cinco anos deve proporcionar experiências que instiguem a criatividade e possibilita descobertas do mundo social e cultural em seu entorno, e esse processo de mediação e demais interações vivenciadas em uma instituição de Educação Infantil difere das realidades em um contexto doméstico.

Portanto, é preciso fomentar a pesquisa, suscitando diálogos e discussões a respeito do ensino infantil de forma remota, considerando que as medidas tomadas em relação ao envio de atividades xerocadas para a casa das crianças e/ou às aulas virtuais não minimizam os prejuízos causados pelo avanço de COVID-19 ao calendário escolar, uma vez que a educação das crianças em creches e pré-escolas é de natureza essencialmente interacional.

\section{O ENSINO REMOTO NA EDUCAÇÃO INFANTIL: RESULTADOS E DISCUSSÕES}

Inicia-se esse diálogo afirmando que a discussão de dados de pesquisa contribui, significativamente, para o desenvolvimento do conhecimento científico, na medida em que favorece a análise do contexto social, econômico e político. Dessa maneira, na perspectiva deste estudo, os dados foram organizados a partir de categorias delimitadas, de acordo com as perguntas e as respostas dos interlocutores. Assim sendo, as duas primeiras perguntas propostas nesta pesquisa estão relacionadas com a idade da criança e o tipo de instituição de Educação Infantil.

A primeira pergunta mostra as idades das crianças matriculadas na Educação Infantil de acordo com a resposta dos interlocutores da pesquisa. Conforme os dados, 30,6\% das crianças têm cinco anos; 24,5\%, quatro anos; 28,6\%, três anos; $14,3 \%$, dois anos; e 2\%, um ano de idade. Observa-se, a partir da análise dos quantitativos citados anteriormente, que a maioria está finalizando a etapa da Educação Infantil, uma vez que 30,6\% apresentam cinco anos, idade máxima para concluir a pré-escola.

Também se colocou em discussão o tipo de instituição de Educação Infantil. Observa-se que 84\% das crianças estão matriculadas na rede particular de ensino e que $16 \%$ delas estão na rede pública. Nesse contexto, uma questão a se ressaltar está relacionada, no caso de Teresina-PI, ao fato de que as aulas remotas nas escolas particulares iniciaram no mês de abril, enquanto as escolas públicas retomaram suas atividades, por meio do ensino remoto, no mês de junho. Destaca-se que a rede particular de ensino oferece condições bem mais favoráveis ao ensino remoto, uma vez que os pais e/ou responsáveis das crianças possibilitam o acesso às plataformas digitais, por intermédio de computadores, tablets, celulares, dentre outros aparelhos. Já na rede pública, os pais, muitas vezes, não têm acesso à internet e, além disso, não têm suporte tecnológico, o que amplia, assim, as desigualdades sociais e ressalta a diferença de possibilidades de estudo, em comparação à realidade do ensino particular.

A matéria "Pandemia amplia abismo entre escolas públicas e privadas no Brasil" foi noticiada na Folha de S. Paulo no mês de maio de 2020. Ela ressalta o abismo socioeconômico existente no Brasil, em relação ao acesso a serviços de educação, saúde e distribuição de renda, uma vez que a maioria das escolas públicas não tem condições de oferecer o ensino remoto às crianças. "Na educação, estamos constatando a enorme disparidade entre os serviços das instituições públicas e privadas e as condições de estudos de jovens de diferentes classes sociais” (THOMPSON, 2020, p. 1). 
Diante da realidade evidenciada nas linhas anteriores, traz-se à reflexão a seguinte inquietação: o ensino à distância substitui o presencial na Educação Infantil? Os interlocutores foram bem enfáticos ao afirmarem que não substitui, reiterando a importância da socialização, das brincadeiras e da troca entre os pares. Ressalta-se, nesse intento, a fala de um dos colaboradores da pesquisa, que diz: "Nada substitui o ensino na Educação Infantil. Há vários fatores que precisamos observar na criança. A BNCC nos mostra vários campos de experiência a serem trabalhados com a criança. Por isso, o ensino presencial é fundamental para o desenvolvimento progressivo da criança".

Em observância à fala do interlocutor, destacam-se a BNCC e os seus campos curriculares, que enfatizam habilidades e atitudes que devem embasar a aprendizagem de crianças de zero a cinco anos, ressaltando a importância da experiência vivenciada no ambiente escolar. Assim sendo, respeitando os direitos de aprendizagem e desenvolvimento da criança, o referido documento curricular determina cinco campos de experiências. São eles: o eu, o outro e o nós; corpo, gestos e movimentos; traços, sons, cores e formas; escuta, fala, pensamento e imaginação; espaços, tempos, quantidades, relações e transformações.

Em relação ao campo intitulado “o eu, o outro e o nós”, a BNCC sobrepuja sobre a necessidade da interação social para o desenvolvimento da criança, fato que não acontece no ensino a distância, já que "[...] é na interação com os pares e com adultos que as crianças vão constituindo um modo próprio de agir, sentir e pensar e vão descobrindo que existem outros modos de vida, pessoas diferentes, com outros pontos de vista” (BRASIL, 2017, p. 40).

Na perspectiva, nesse intento, a respeito de como as instituições de Educação Infantil estão oferecendo aulas e/ou atividades remotas para as crianças, obtiveram-se respostas diversas. Aulas pela plataforma digital, aulas por WhatsApp, vídeos gravados, tarefas, ligações semanais, projetos de leitura, materiais entregues por drive-thru, dentre outras ações, foram algumas das atividades citadas pelos pais. Nesse sentido, considera-se que, de forma a tentar adequar as crianças à nova rotina imposta pela pandemia de COVID-19, as escolas replanejaram suas atividades, tomando como base o ensino remoto. Dessa forma, instituição escolar e família têm tentado adaptar as crianças a essa nova forma de aprendizagem. Entretanto, é importante salientar que a realidade apresentada é notória na rede particular de ensino, uma vez que a maioria das crianças está matriculada nas escolas particulares, no caso do estudo.

Diante dessa nova realidade, faz-se necessário citar o Parecer n. ${ }^{\circ}$ 5/2020, aprovado em 28 de abril de 2020. O documento trata da reorganização do calendário escolar, com a possibilidade de considerar as atividades não presenciais para cumprimento da carga horária mínima anual, tendo em conta o período de pandemia. O Parecer traz orientações a respeito de atividades a serem desenvolvidas com as crianças. Todavia, inicialmente ressalta uma questão importante: “[...] de não haver previsão legal nem normativa para oferta de educação a distância, mesmo em situação de emergência”. (CONSELHO NACIONAL DE EDUCAÇÃO, 2020, p. 9).

Dessa maneira, o Parecer foi homologado, com o objetivo de contribuir para minimizar eventuais perdas para as crianças, no sentido de orientar pais e professores acerca de atividades lúdicas e interativas, evitando, assim, retrocessos nos mais diferentes aspectos. Finalizando esse momento de análise inicial, evidenciando que são apenas os primeiros passos de uma ampla discussão no âmbito científico, apresentam-se as dificuldades encontradas pelos pais no acompanhamento dos seus filhos, considerando-se essa nova forma de ensinar.

Dessa maneira, observa-se que $28 \%$ dos pais não encontram dificuldade e que $72 \%$ deles apresentam algum tipo de dúvida e/ou inquietação. É importante citar, em primeiro lugar, pelas respostas analisadas, que, dessa porcentagem que não apresenta dificuldades, tem-se a presença de pais que são professores e que conhecem o processo de ensino-aprendizagem e as discussões relacionadas à didática. "Não sinto dificuldades, pois sou professora. Mesmo sendo docente do ensino superior, a gente passa a ter mais experiência nesse processo de aprendizagem do que algumas outras mães”, afirma uma das interlocutoras da pesquisa. 
Porém, na maioria das falas, atenta-se para muitas angústias e inquietações, devido a questões relacionadas à dificuldade de conciliar trabalho, organização das tarefas domésticas e acompanhamento das atividades escolares dos filhos, além do desconhecimento das metodologias de ensino no contexto da Educação Infantil. "Estou em teletrabalho de dois turnos. Não disponho do tempo necessário que as atividades demandam. E a criança reage diferente no ambiente de casa”, ressalta uma interlocutora. As respostas dos colaboradores reafirmam o que os autores trazem a respeito da importância do trabalho do professor na Educação Infantil. Segundo Oliveira et al. (2012, p. 58), “[...] é o professor quem planeja as melhores atividades, aproveita as diversas situações do cotidiano e potencializa as interações”.

Portanto, o docente tem um papel fundamental, uma vez que ele possibilita a construção de sua identidade e sua autonomia, considerando a criança membro da sociedade. Em conclusão dessa análise, afirma-se que a função de mediar e produzir conhecimentos, juntamente às crianças da Educação Infantil, é atividade do professor. “Pais são pais, jamais substituirão os professores”, evidencia uma colaboradora da pesquisa.

\section{CONSIDERAÇÕES FINAIS}

O ensino infantil em instituições formais assegura que a criança aprenda em situações diversas, possibilitando a ela desempenhar um papel ativo na construção de significados sobre si, os outros e o mundo em que vive. Desse modo, a vivência escolar é indispensável para o desenvolvimento e a aprendizagem das crianças que têm de zero a cinco anos, e a escola é uma instituição importante para garantir que elas aprendam e se desenvolvam com as interações e a brincadeira.

Desse modo, o trabalho pedagógico nas creches e nas pré-escolas é desenvolvido de forma dinâmica e flexível, proporcionando à criança maior facilidade de organização espaço-temporal, assegurando o direito à proteção e promovendo a qualidade da vida em grupo, o que não se torna possível com atividades remotas de forma virtual ou com atividades xerocadas enviadas para os seus lares. Muitas crianças vivem com famílias de baixa renda, sem estrutura financeira e psicológica, com pais analfabetos e sem condições tecnológicas e afetivas para um acompanhamento pedagógico feito pelos pais e/ou responsáveis que não tenham uma formação pedagógica para o ensino infantil.

A pesquisa desenvolvida possibilitou uma compreensão da concepção das famílias em relação ao ensino remoto na Educação Infantil e, também, reiterou a necessidade de uma reflexão a respeito do momento em que as crianças estão vivendo, de isolamento social, no sentido de que muitas estão em convívio familiar, em diferentes contextos sociais e emocionais nos quais a sobrecarga de atividades escolarizadas em casa poderá aumentar o estresse de crianças e adultos. 


\section{REFERÊNCIAS}

BARDIN, L. Análise de conteúdo. São Paulo: Edições 70, 2011.

BRASIL. Ministério da Educação e do Desporto. Lei de Diretrizes e Bases da Educação Nacional. Brasília: MEC, 1996.

BRASIL. Ministério da Educação e do Desporto. Base Nacional Comum Curricular. Brasília: MEC, 2017.

BRASIL. Constituição. Constituição da República federativa do Brasil. Brasília, DF: Senado Federal, 1988.

BRASIL. Ministério da Educação. Diretrizes Curriculares Nacionais para Educação Infantil. Brasília: MEC, SEB, 2010.

BRASIL. Ministério da Educação. Referencial Curricular Nacional para a Educação Infantil. Brasília: MEC, Secretaria de Educação Fundamental, 1998.

CONSELHO NACIONAL DE EDUCAÇÃO (Distrito Federal). Parecer CNE/CP No: 5/2020, de 28 de abril de 2020. Reorganização do Calendário Escolar e da possibilidade de cômputo de atividades não presenciais para fins de cumprimento da carga horária mínima anual, em razão da Pandemia da COVID-19. Diário Oficial da União, Brasília, 1 jun. 2020, seção 1, p. 32, 28 abr. 2020. Disponível em: http://portal.mec.gov. br/index.php?option=com_docman\&view=download\&alias=145011-pcp005-20\&category_slug=marco-2020pdf\&Itemid=30192. Acesso em: 27 jul. 2020.

FLICK, U. Introdução à pesquisa qualitativa. 2. ed. Porto Alegre: Artmed, 2004.

MOREIRA, H.; CALEFFE, L.G. Metodologia da pesquisa para o professor pesquisador. Rio de Janeiro: DP\&A, 2006.

MOURA, A.F; LIMA, M.G. A reinvenção da roda: roda de conversa, um instrumento metodológico possível. Temas em Educação, João Pessoa - PB, v. 23, n. 1, p. 98-106, jan./jun. 2014.

OLIVEIRA, Z.M.R. et al. O trabalho do professor na educação infantil. São Paulo: Biruta, 2012.

PIAUÍ. Decreto $n^{\circ}$ 18.884, de 16 de março de 2020. Regulamenta a lei no 13.979 , de 06 de fevereiro de 2020, para dispor no âmbito do Estado do Piaú, sobre as medidas de emergência de saúde pública de importância internacional e tendo em vista a classificação da situação mundial do novo coronavírus como pandemia, institui o Comitê de Gestão de Crise, e dá outras providências. Palácio de Karnak, Teresina, 16 mar. 2020. Disponível em:https://www. pi.gov.br/wp-content/uploads/2020/03/Decreto-18.884-de-16-03-2020.pdf . Acesso em: 27 jul. 2020.

THOMPSON, M. Pandemia amplia abismo entre escolas públicas e privadas no Brasil. Folha de S. Paulo, ano 100, n. 33.295, maio. 2020. Disponível em: https://www1.folha.uol.com.br/educacao/2020/05/pandemiaamplia-abismo-entre-escolas-publicas-e-privadas-no-brasil.shtml. Acesso em: 27 jul. 2020. 